\title{
Learning to be a professional football manager: A Bourdieusian
}

\section{perspective}

\section{Stephen Morrow and Brian Howieson}

\begin{abstract}
This paper draws on the theoretical concepts of Pierre Bourdieu to provide an insight into aspirant football managers' perceptions of what is required and valued at different stages of their desired managerial career journey. Drawing on interviews with candidates from one cohort of the SFA Pro-Licence ( $n=19)$, our evidence suggests that aspirant managers have responded to changes in field logic by adopting strategies which place increased emphasis on cultural capital in the form of engagement with educational discourse. While we find evidence of instrumentality in attitudes to education, we also find evidence which emphasises the importance of habitus as an unconscious process. Educational culture is absorbed and embodied by some aspirant managers, which enlightens their actions and encourages them to adopt empowering strategies through which they seek to transform their place in the field. The paper concludes by considering potential implications for governing bodies and clubs.
\end{abstract}

Key words: Professional football managers, Pierre Bourdieu, education 


\section{Introduction}

The football manager (hereafter 'the manager') remains a pivotal figure in almost all British football clubs ${ }^{1}$. Ultimately, the manager's principal objective and one which he/she continues to be solely accountable for remains as it always has been - winning football matches in a competitive environment in which there will always be many more losers than winners and in which their performance is publicly and continuously scrutinised (Morrow \& Howieson, 2014). As a result football management is a highly risky career. Most managers suffer the indignity of being sacked at least once in their career and the average tenure of managerial positions is some leagues has fallen to little more than a year ${ }^{2}$. And yet, despite this unforgiving environment, the demand for managerial positions appears higher than ever.

In his comprehensive history of the changing role and status of the football manager from Victorian-era amateurism through to its modern incarnation, Carter (2006) identifies the period between 1945 and 1970 as coinciding with the modernisation of football management. One feature of this period was the expansion of coaching schemes, initiated originally by the Football Association during the 1930s, these being designed in a loose way to assist directors with their managerial selection (Carter, 2006). Central to that selection process was a taken for granted acceptance that career progression to becoming a manager was predicated on an individual's prior expertise and status as a professional football player (Blackett, Evans \& Piggott, 2017; Kelly, 2008; Morrow \& Howieson, 2014). Interestingly, a number of studies have stressed, however, that experience is not limited to that arising from playing the game. Rather by being embedded in a particular coaching culture, players or athletes learn by

\footnotetext{
${ }^{1}$ European clubs have long employed a Head Coach (with responsibility for the training, development and performance of the first team only) and a Director of Football (a senior management figure with responsibility for all other football related activities and for liaison with other club executives and directors). British clubs, in contrast, have traditionally employed a (football) Manager, whose role and responsibility often extended beyond the responsibilities ordinarily associated with a Head Coach, encompassing the training and development of a club's first team squad of players (which may or may not include carrying out the role of coach), talent identification, youth development, buying and selling of players, and media and public relations activities. In recent years, however, there has been movement within British football towards the so-called European model.

${ }^{2}$ Club managers in England dismissed in 2015- 16 were in post for an average of only 1.29 years (LMA, 2016).
} 
observation which in turn contributes to the informal, field-specific and embodied development of sport-specific coaching content knowledge (Blackett et al., 2017; Cushion, Armour \& Jones, 2003; Jones, Armour \& Potrac, 2003). Such informal learning practice now exists in parallel beside standardised coaching accreditation schemes, the highest level of which is the Union of European Football Associations (UEFA) Pro-Licence.

For a number of years, the authors have provided management education workshops as part of the Scottish Football Association's (SFA) UEFA Pro-Licence programme. Our interactions with participants (aspirant football managers) alerted us not only to an appetite for skill development in such areas as, for example, negotiation and communication, but also among some participants to an apparent interest in education in a broader sense. This impression sat in contrast to academic literature which suggested hostility among footballers and managers towards education as historically the sport's working class roots valued attributes like masculinity and physicality, which may have contributed to a distrust of intellectualism (Carter, 2006; Gearing, 1999; Kelly, 2008; McGillivray \& McIntosh, 2006). This in turn led us to question commonly held perceptions as to what is necessary for an individual to become (and to remain) a football manager. While previous research has focused on, for example, the expectations directors have of coaching and managerial appointments (Blackett et al., 2017) and on approaches to managerial learning and development (Kelly, 2017), few studies have sought to investigate perceptions of football management from among those who seek to become football managers. The principal aim of this study was thus to investigate aspirant managers' perceptions of, and the value they ascribed to, particular experiences, skills and educational engagement (formal and informal) as they sought to progress their careers as football managers in both the short and longer term. 
A Bourdieusian framework has been used to critically examine the evidence obtained from the aspirant managers (Bourdieu, 1977). Bourdieu's sociological framework provides social explanations of everyday life and everyday practices, and has been used extensively in sport settings (Bourdieu, 1978, 1993; Cooper \& Joyce, 2013; Cushion et al., 2003; DeLuca \& Andrews, 2016; Grenfell, 2015; Lenoir, 2006; Light \& Evans, 2013; McGillivray, Fearn \& Macintosh, 2005; Tomlinson, 2004 ${ }^{3}$ ). Bourdieu always began with a practical context - in our case, this is the social setting in which individuals seek to become professional football managers. The relevance of Bourdieu's work in understanding the dynamic social practices found in professional football has been considered previously. Most pertinently for this paper by: Cushion and Jones (2014) in respect of how socialisation and the hidden curriculum within coaching practice contribute to the creation of social identities and the occurrence of symbolic violence; McGillivray and Macintosh (2006) where the focus was on players' engagement with educational discourses; and Blackett et al. (2017) who examined how particular coaching skills and sources of knowledge were valorised by directors of professional football and rugby union clubs.

Central to this paper is habitus - the principles of judgement and practice generated by aspirant managers' previous life experiences (particularly in football) and the extent to which they are modified subsequently (Emirbayer \& Johnson, 2008). At the same time, the concept of capital is key to the functioning of a social space such as a football club. Capital refers to those different forms of power that determine the position of social agents in the social hierarchy (Cushion, 2011). It can be understood as what energises the development of a field (Moore, 2012). The general distinction that Bourdieu makes is between economic capital (that which can be directly converted to money) and symbolic capital, which includes sub-

\footnotetext{
${ }^{3}$ See also, Fry, Bloyce and Pritchard (2015) who use the concept of habitus to examine how professional golfers make sense of their workplace experiences as they seek to reconcile sporting and financial objectives and pressures.
} 
types such as cultural capital (for example, gained through formal education) (Moore, 2012). Bourdieu suggests that symbolic capital is the form different types of capital take once they are perceived and recognised as legitimate (Bourdieu, 2006). Of particular interest is aspirant managers' perceptions on what is valued or recognised as symbolic capital in their field at particular points in time.

To achieve our research aim, this paper will proceed as follows. First, we will introduce in more detail Bourdieu's Theory of Practice and the inter-related notions of field, habitus, and capital. Thereafter, our approach to this research including methodology will be set out. In the following section, we will present our results and discussion. Thereafter we will provide insight into different forms of capital that embody the habitus of individuals at different stages of the football management journey, and in particular on the appetite for education apparent among aspirant managers within our sample. Finally we consider possible implications for key actors in the football field.

\section{Theoretical background}

What Bourdieu's conceptual framework seeks to address is the dialectical relationship between the actions of individual social agents within a particular social arena or field and the manner in which the associated social structures shape such actions (Blackett et al., 2017). The concept of field is a structured social space - an organised and objective network of social relations where agents compete for resources and position using different strategies to maintain or improve their position (Jarvie \& Maguire, 1994; Kitchin \& Howe, 2013).

Similar to the way in which a football field is a boundaried site where a game is played, the social field consists of positions occupied by people or institutions and what happens on or in the field is boundaried (Thomson, 2012). Each field has its own distinctive logic of practice and collectives of people may occupy more than one social field at a time. 
The field is a system characterised by a series of power relations where capital is a form of power. Possession of one or more forms of capital allows those in possession to 'wield a power, or influence, and thus to exist, in the field under consideration' (Bourdieu \&Wacquant, 1992: 98). The extent to which they have the capacity to impact upon, change or control situations depends on the amount of capital possessed and also on the value placed upon it within any particular field (Emirbayer \& Johnson, 2008). The challenge is not to take these capitals one by one and analyse them separately, but rather to see how they interact in the case of specific practices and social classes in acknowledgement that capital only exists and functions in relation to a field (Bourdieu \& Wacquant, 1992). Moreover, the forms of power, too, will be closely connected to habitus.

In any field, the dominant form of capital in circulation governs what is of value and what, therefore, can be exchanged, allowing the dominants within that field to exercise power over the field as a whole. While economic capital is widely understood, Bourdieu introduced the notion of field specific symbolic capital; sub-types of capital such as cultural capital or scientific capital whose form and use are recognised through our categories of perception as legitimate bases of social position in society (Cooper \& Joyce, 2013) ${ }^{4}$. Bourdieu refers to the results of such domination as symbolic violence (Schubert, 2012). Hence, capital helps us understand how advantage, distinction, and ultimately, domination, are reproduced in and through fields.

The third level of any field analysis is habitus - those aspects of culture that are absorbed and embodied in the daily practices of individuals and which reflect the norms of groups, societies, and nations (Jenkins, 2002). As an orientating idea, habitus works by drawing attention to something significant and offering a way of thinking about it (Maton,

\footnotetext{
${ }^{4}$ For example, Tomlinson (2004) offers the example of the Marylebone Cricket Club at Lords Cricket Ground in London where several forms of capital are drawn upon to construct and create a particular dominant class and patriarchal habitus. These 'smart clubs' constitute an exclusive and privileged class habitus, in which particular combinations of capital (in this case educational, cultural, and economic) will determine one's suitability to enter the habitus.
} 
2012). According to Bourdieu, habitus can be defined as a system of dispositions, appreciations, and perceptions which work to shape attitudes, behaviours and responses to given situations in the fields that we inhabit (Kitchin \& Howe, 2013; Webb, Schirato, \& Danaher, 2002). Importantly, habitus is a system of dispositions that is acquired through socialisation (Schinkel, 2007). The dispositions — like field logic — hence determine what is and what is not considered acceptable (Kitchin \& Howe, 2013). Habitus thus links the decision-making of individuals to wider social structures and it disposes actors to behave in certain ways (Cushion \& Jones, 2006). But at the same time, habitus is not deterministic, as it also captures the creative possibilities of individual actions which enable the transformation of normalising practices (Blackett et al., 2017). Hence, while agents are influenced by the structural conditions of the field they practice within, they also have the opportunity to change the habitus of the field (Bourdieu, 1984). So while practice shapes habitus, habitus in turn unifies and generates practice (Cushion \& Jones, 2014). Moreover, it is important to stress the inter-related nature of Bourdieu's thinking tools in that practices - within a particular field - are not merely the results of an individual's dispositions or habitus but rather, and of note, of relationships between the habitus and their current position within that field (Maton, 2012).

\section{Methodology}

\section{Research context of the study}

It is as recently as 2003, that the governing body of European football, UEFA, sought to formalise the role of the football manager by introducing the requirement that an aspirant manager must hold a UEFA Professional Licence (Pro-License) - the highest level in its coaching pyramid - in order to take up a management position in the top level of any European nation's league system (UEFA, 2012, Articles 36, 40). The focus of the ProLicence is on how to manage (in contrast to how to coach) and hence some of its focus is on 
matters 'off' the football field. Several national associations' Pro-Licence programmes, including the SFA's, now also include business and management workshops or seminars, these often being led by university academics with expertise in management as opposed to coaching. For example, our input to the SFA Pro-Licence introduces aspirant managers to areas like football finance, negotiation and influence, and leadership, and the teaching philosophy adopted seeks to develop and encourage critical thinking skills among the participants. Our experiences of working with aspirant managers through the Pro-Licence acted as the catalyst for the development of our research, leading us to question commonly held perceptions as to what is necessary for an individual to become (and remain) a football manager.

\section{Participants}

The participants in the study were drawn from a single cohort of the SFA's Pro-Licence course. It is acknowledged that our roles as educators and researchers on this programme could be perceived as providing a conflict of interest. However, it is only our involvement in the SFA's Pro-Licence that has enabled us to establish a degree of trust with aspirant managers attending the business management workshops and with representatives of the governing body itself. Hence, it is worthy of note that all participants $(n=22)$ in one of the recent cohorts were receptive to an invitation — informally presented at one of the workshops, followed up with written information and a consent form - to take part in a research study focusing on aspects of football management and leadership, this being based on individual interviews. Prior to this, ethical approval had been given by the relevant university Ethics Committee. Ultimately, 19 of the 22 participants on the Pro-Licence were interviewed (the 'interviewees'). Three individuals were unable to participate within the timescale due to work and/or personal circumstances. Thus, our sample includes almost all of those individuals who would become qualified from within a particular football country to 
take on an elite-level managerial role in any UEFA country during that particular two-year period.

At the time of the interviews, the individuals $(n=19)$ held a variety of positions in football and beyond. Information on their employment status at that juncture, as well as subsequently, along with other background information covering age, experience, gender and educational experience is set out in Table 1.

[insert Table 1 here]

\section{Methods}

Semi-structured interviews were held with each individual to ensure an in-depth and as rich a source of data as possible, allowing interviewees the time and space to provide their personal views, attitudes and opinions and to capture their subjective meaning in contextual situations (Potrac, Jones, \& Armour, 2002). Cognisant of a potential conflict in our roles as educators and researchers, we stressed to participants that the research project was designed to be reflective and that their opinions and views were not seen as validation or otherwise of any part of the Pro-Licence course. In the context of this paper, the questions focused on: their preparedness for managerial positions; their experiences and attitudes towards the ProLicence and, in particular, the business management workshops; their views on management learning and education more widely; and their views on how one becomes a manager. Interviews began with introductory questions about the interviewee's background, in football and more generally, thus allowing the researchers to develop a rapport with them. The majority of interviews $(n=13)$ were conducted on a face-to-face basis with managers in their football working environment. Geographical considerations resulted in the other interviews being conducted by telephone $(n=6)$. The average length of the interviews was 51 minutes 
and all interviews were transcribed resulting in 349 pages of single-spaced material. Access to an entire Pro-Licence cohort in one country provides a deep insight into aspirant managers' perceptions of what is required to be a football manager and how this relates to the educational and coaching structure.

\section{Analysis}

Access to any social world is through the explanations given by the people who inhabit that world. These accounts comprise the concepts used by those individuals to structure their world - the meanings and interpretations, and the motives and intentions which direct their behaviour (Bryman \& Bell, 2015; Sparkes \& Smith, 2014). As such, an abductive research approach, framed by interpretivism, was considered the most appropriate way to analyse the interview data collected in this project. This approach involved inductive thematic analysis of the interview data combined with deductive abstraction of these themes within the context of a Bourdieusian framework, following the approach used in related studies (Townsend \& Cushion, 2017).

The first stage of the analysis involved each interview being read independently by both researchers. Each researcher then sought to order interview quotes around common themes. The data was then inductively examined for themes that the researchers considered captured experiences and perceptions of the process of becoming a football manager. In the next stage a deductive approach was utilised by applying Bourdieu's concepts, resulting in three themes for discussion: habitus and managerial appointment; changing habitus - taking on the role of a manager; and reconfiguration of the field.

\section{Results and discussion}

\section{Habitus and managerial appointment}

The traditional route by which an individual becomes a manager in European football has emphasised two elements: first, the expectation of previous playing experience (renown 
as a player): and second, the importance of learning by doing (Bridgewater, 2010; Carter, 2006; Kelly, 2008; Wilders, 1976). Renown as a player has been accepted by many directors and club owners - key gatekeepers in managerial careers - as indicative of management ability and thus suggests a form of symbolic capital, recognised by key actors in the field and by the rules of the field as legitimate, valid, and useful (Iellatchitch, Mayrhofer \& Meyer, 2003; Morrow \& Howieson, 2014) ${ }^{5}$. Blackett et al. (2017) found that fast tracked appointments in football and rugby were often based upon directors' perceptions as to whether appointments would gain and maintain their players' respect. This perception was based in part on player renown, but also an assumption that those prior experiences would provide individuals with the ability to develop practical sense and an elite sporting habitus appropriate to the requirements of the field. Our interviewees' perceptions reinforced this view; recognising the near necessity of playing renown to secure a job - a source of frustration to those interviewees with limited playing experience - but also recognising that it was not a durable form of capital; that respect had to be quickly earned on the training field and in results.

That credibility for well-known players only lasts until your first training session or your first match. (Interviewee 5)

Since 2003, holding a UEFA Pro-licence has been a pre-requisite to take up a management position in the top level of any European nation's league system (UEFA, 2012,

\footnotetext{
${ }^{5}$ A recent example from Scottish football demonstrates the willingness of some clubs to challenge this traditional view of what constitutes symbolic capital in terms of football management, while at the same time emphasising how deep routed traditional perceptions remain among others in the field. Specifically, the decision by Scottish Premiership club, Heart of Midlothian, to appoint former Newcastle United, Valencia and Rio Ave coach, Ian Cathro as its new Head Coach was greeted with outrage by some players /ex-players, their concern centring on his lack of experience around seasoned professionals - Cathro has no elite level playing experience - and on his putative 'academic' approach to coaching. See, for example, Liew (2016) and Murray (2016). Cathro was sacked by the club after only seven months after a poor run of results.
} 
Articles 36, 40). Grenfell (2015) suggests that one condition of a field is its search for autonomy. Professional football can be considered a relatively autonomous field in which governing bodies (transnational and national) institutionalise rules and regulations as to how the game is to be played and managed (Gammelsæter, 2010). Its producers - leagues and clubs - in cognisance of their own interests, act to legitimise and control what is recognised and valued in the field, leading in turn to a field logic or logics. In the context of our study, actors are attuned to the rules of the game which underlie practices in the field - coaching qualifications as part of a specified coaching pathway are, therefore, necessary because they have been deemed so by football's gate-keepers, the governing bodies. For example:

As a player, I thought [coaching courses were] something you had to do. Without a shadow of a doubt ... you've got to do this to become what you wanted to be, a coach or a football manager. (Interviewee 18).

Such views reflect an acceptance of the established operating logic of the professional football field. It also demonstrates how habitus links the social and the individual: while the experience of one's life course may be unique in its particular contents, it is shared in terms of its structure with others of the same social class, gender and particularly in this case, occupation (Maton, 2012). Habitus thus links the decision-making of individuals to wider social structures, disposing actors to behave in certain ways (Cushion \& Jones, 2006).

\section{Changing habitus: taking on the role of a manager}

The greater institutional emphasis on coaching and managerial qualification from gatekeepers like UEFA and national associations could, therefore, be expected to reinforce the 'accepted rules of the game'. There are two dimensions to this. The first is that clearly aspirant managers require to accept that becoming a manager is conditional on undertaking 
the Pro-Licence, including its educational aspects. Secondly, however, individuals who constitute any Pro-Licence cohort have all come through a similar coaching education process. Moreover entry to the Pro-Licence is not automatic, with applicants selected on criteria which include experience in the professional game (see, for example, Football Association, 2016; Scottish FA, 2016). Numbers are restricted and both associations note that meeting the entry criteria does not guarantee an applicant a place on the Pro-Licence. Acquiring a Pro-Licence, therefore, allows individuals to exercise power or influence, and thus to continue to exist in the field (Bourdieu \& Wacquant, 1992). In our study there is certainly evidence of interviewees responding to the Pro-Licence and its requirements in an instrumental way. At the same time, however, what is also apparent among a number of individuals is an explicit recognition of the value that this type of capital (educational) provides within the field per se. Rather than being constrained by their previous experiences in the field and focusing solely on its accepted rules, instead we see evidence of aspirant managers apparently enlightened by their habitus:

Having been on [various courses] I'm a totally different ... person from a coaching [and] managerial sense than I was two or three years ago. Totally different. Better hopefully from it. ... So if I continue to have that education ... I am sure that I'll be better than I am now. (Interviewee 18)

And every time we go on the Pro-Licence, I learn something. ... Going through the Pro-Licence course and everything that we're doing and everything you are teaching us and making us aware of ... (Interviewee 4). 
At my first club as a player, I learned an incredible amount that stuck and it's the same with this course. [An] incredible amount of things. We've had to deal with the coaching side, getting on with the people within it, the assessment, the computer scenario, this management sort of side of things, board room and relationships. It's brilliant and it's such - there's an awful lot there but it definitely opens your eyes to it all and for me it's absolutely vital. ... it's been probably the most important thing that I've done in years because it's what I want to be doing and there's very few places you can actually learn these things other than thrown in at the deep end. (Interviewee 2).

Such comments suggest an internalising of an external regulation, where the content of courses such as the Pro-Licence is increasingly valued and endorsed by some individuals attending those courses on its own merits (Deci \& Ryan, 1985; McLean, Mallet, \& Newcombe, 2012; Ryan \& Deci, 2000). The habitus, as well as interpreting the conditions of the social space in which aspirant managers are situated, also generates action (Schinkel, 2007). For example:

I know I want to learn as much as I possibly can to make me better. Therefore, [the Pro-Licence is] making me better, it's making people I know much better. That's the way I look at it. (Interviewee 17).

That will be quite interesting; trying to implement some of the things you've been talking about. For me, the management course was great. It reaffirmed a lot of things I knew, it also broadened my [perspective on football management]. (Interviewee 14). 
That agents are both dialectically influenced by the structural conditions of the field they operate within, while at the same time have the opportunity to change the habitus of the field lies at the core of Bourdieu's investigation into various fields (Bourdieu, 1984). Recognising that the capital which facilitates entry to the field - symbolic capital in the form or renown as a player - is not in itself longer sufficient, aspirant mangers adopt strategies which emphasise alternative forms of capital - in this case, educational capital. Significantly, their dispositions are not closed off by their previous experiences or by the relational structures of habitus and field. Rather, we see evidence of the evolution of the field in which the aspirant managers are situated and the evolving habitus which those actors bring to the field of practice (Bourdieu, 1990).

In the interviews, the more explicit academic elements of the Pro-Licence were welcomed by several individuals. For example:

My own biggest bugbear is that I am not academic in terms of having a qualification. But I think that what it has made me do is educate myself further and develop myself further as a person because I always want to learn and I think that's a massive, massive thing to be open minded to learning. I must admit, the challenges and the assignments that we've had on this course even the last one handing it in to [the] Uni[versity] [and] being marked independent [of the SFA] - that's something I've never done and probably a lot of people on the course are similar and I think, looking back on it, Jesus, education is so much. Brilliant. Absolutely fantastic. (Interviewee 9).

People ask me 'why am I going 15,000 miles for one weekend'? And I said, for one reason, for education. It's not about just going, here's my certificate, I've got one. No, it's what I get out of it and that's education. It's how do I make myself better [for] the 
next time I ... get a job ... whether it's again as [a] football manager or will I get a job managing something completely different but I think this is definitely going to help in the long run. (Interviewee 6).

Experiential learning or 'learning by doing' is central to the habitus many former players bring to management at the outset, this coupled with their managerial and coaching socialisation gained at a variety of clubs during their careers (Blackett et al., 2017). Through the Pro-Licence, candidates are then provided with a structure which both encourages them to share experiences and to focus on the different social worlds which they seek to become part of. What is presented in our interview data is an appetite among aspirant managers to learn about the qualities and developed-learning appropriate to the new road to be travelled, signifying a desire to challenge the social order and the natural way of doing things.

Thus how individuals acquire taken-for-granted understandings that inform practical action is influenced not only by primary habitus (notably class conditions surrounding their earlier lives) but also by specific habitus (e.g. organisational settings such as the Pro-Licence in which they are active later in life) (Vaughan, 2002). As such, the habitus of the aspirant managers is to some extent transformed by the professionalisation of their occupation, a transformation initiated by transnational and national governing bodies. This embodied culture provides the basis for a particular set of 'durable transposable dispositions'; ways of acting, seeing and making sense of the world (Bourdieu, 1977). Hence, prospective managers are getting a 'feel for the game' and improvising in an attempt to improve their position within their particular field (Bourdieu, 1990; Maton, 2012).

\section{Reconfiguration of the field}


The professional football field has always been characterised — and indeed, seeks to characterise itself — as a relatively autonomous field, with responsibility for self-regulation in areas, for example, as diverse as employment and contractual regulation, on-field misbehaviour and violence, and financial regulation. Within this context, the enthusiasm of actors to reformulate their identity from beyond the boundaries of the field - in one sense, to reconfigure the field is illuminating:

So I think the more that we look out with our own business, I think we'll get better because I think that we can learn so much ... I think everybody would get better by looking at different things; again by just checking out [how other organisations] do things because there'll be situations that arise in our careers if we had some more insight, we might have dealt with them a different way. (Interviewee 6).

I think football is very different to a lot of sort of organisations but I think football [has caught up in the last few years] but I've been amazed by this course how much detail we have gone into about management and leadership. So I do think football's learning from other things ... (Interviewee 7).

Emphasis on ways in which the field is being reconfigured are evident elsewhere too. Bourdieu and Wacquant (1992: 76) defined the field of power as a 'field of struggles for power among the holders of different forms of power'. While football has had a commercial dimension since the late 1800s when professionalism was legalised by the Football Association (Collins, 2013; Vamplew, 1988), professional football has undergone a remarkable financial transformation in recent decades, inevitably altering the relationship between the holders of different forms of power. This transformation has seen emphasis 
increasingly move from football's social and cohesive role, to its role as a source of commercial exploitation, with implications for structures and relationships (Grenfell, 2015). What was apparent from our interviews was a perception of changes in their social field in relation to other fields, and in particular to the field of power:

Football is becoming more and more of a business, especially the higher up the leagues you go. So the business aspect of it and management side of things are very, very closely tied I think. (Interviewee 3).

In addition, while the majority of interviewees indicated their comfort with the football side of management, their preparedness to deal with non-football matters, specifically those concerned with business or financial issues, was readily identified as a concern. For example:

Some managers I know do like that [financial] stuff but they see themselves as a bit of a businessman. ... I don't think I'll ever be that way.... The challenge is I've got to embrace that as much as I can because I know that that is part of [managing] especially now, I know the game's changed from 20 years ago. (Interviewee 1).

At the level of the field, increasingly, economic capital has become the symbolic capital, with ever increasing emphasis on the financial power of major clubs and their owners, media companies, and commercial sponsors (Dobson \& Goddard, 2011; Morrow, 2014). Moreover, other forms of capital previously seen as symbolic are increasingly defined with reference to their potential for translation into goods and services. One example is the focus on leveraging financial benefit from a club's corporate social responsibility activities (Hamil \& Morrow, 2011). One interpretation is that the field has been colonised and the 
logic of the field transformed; this, in turn, has led to change in the dominant habitus. But while an increased emphasis on financial capital is most apparent at the higher echelons of football, arguably among larger clubs the manager's position has become more specialised and hence less likely to require specialist financial knowledge. In contrast, in smaller clubs or in clubs operating in more straitened financial circumstances, financial logic may now have much greater implications for the manager.

\section{Conclusion and implications}

Football remains a - perhaps the - results business. What matters most to managers when they are in post is success - defined relative to their club's expectations - as it is that success which will keep them in employment. If an individual is successful the field assumes that individual has particular qualities that distinguish them as a manager; qualities that enable them to get more from their team than the sum of its parts. As such the professional football field possesses a distinct logic and hence constructs, promotes, and reinforces a particular habitus within which certain kinds of capital are more highly valued. Winning games and/or trophies is seen as symbolic capital and it is this capital which determines the upward positional mobility of a manager (Schinkel, 2007). Yet, at the same time, the business transformation of football and its clubs over the last couple of decades and the increased emphasis placed on economic capital by fields actors such as owners and directors has had major ramifications for the football manager. Moreover, other actors in the field, notably national and transnational governing bodies, have sought to emphasise a more professional field logic, specifically the requirement for managerial education.

Notwithstanding the importance of football success, our study provides insight into different institutionalised forms of capital that make embodied a habitus, the principle of which is congruent with the dominant principles of the field at different points in time. Crucially, we have shown that agents are both dialectically influenced by the structural 
conditions of the field - in this case the notion of playing renown as symbolic capital at the start of a managerial journey or the importance of formal qualifications such as the Prolicence - while at the same time recognising they have opportunity to change the habitus. While for some aspirant managers undertaking the Pro-Licence is simply an instrumental response, our evidence suggests that others have responded to the professional field logic by adopting strategies which place increased emphasis on educational capital, specifically on engagement with educational discourse and critical thinking about the nature of the management role.

Habitus is a system of dispositions that is acquired through socialisation. Over time, wider culture - in this case educational culture and the importance of managerial learning is shared, absorbed and embodied by the aspirant managers, which, in turn, enlightens their actions. Aspirant managers adopt empowering strategies through which they seek to transform their place in the field. What we see, therefore, is individual habitus coinciding with and reinforcing the field logic emerging from national and transnational bodies. Hence, our study offers evidence that the managerial accreditation and education system has both structured the field for aspirant managers and contributed to a changing managerial habitus.

While our study is based only on one Pro-Licence cohort in one country, nevertheless our findings are likely to be of interest to national associations in terms of reflecting upon how they draw up their educational programmes, specifically with regard to their Pro-Licence programme content, but also in terms of embedding educational discourse throughout the coach education pathway. In terms of the former this might include sessions on the importance of critical thinking, particularly in terms of challenging aspirant managers' assumptions about the nature of the organisations they seek to work with and the likely nature of their roles therein. With regard to the latter, exposure to leadership theory, thinking and practice, throughout the coach education pathway, may well be beneficial to programme 
candidates. Moreover, there are also potential implications for national associations and clubs in terms of reflecting on what types of capital are valued or considered symbolic when applications are received for Pro-Licence courses and when managerial appointments are made.

\section{Suggestions for further research}

Literature around football management remains undeveloped and this study identifies several opportunities for further research. Our intention is to develop this preliminary study into longitudinal research, focusing on these individuals as they take on managerial positions throughout their careers and on the structured and structuring nature of habitus. Furthermore such longitudinal research provides an opportunity to reflect on the value and usefulness of the coaching and managerial certification process specifically, and of education in general. Consideration will also be given as to how to expand this study into a field level analysis, providing an opportunity to explore the perceptions of other key actors in the field notably directors and officials who recruit and dismiss managers.

More generally, research questions also emerge which focus on the attitude and approach of club directors to the role of the football manager. As is well understood, by definition, team sport is a zero sum game - even if all managers become better managers, the same number will continue to fail in terms of the principal objective of winning games and competitions (Gammelsæter, 2013). This leads to the paradoxical situation where ever more qualified and educated coaches and managers are losing their jobs with higher frequency than ever before (Nissen, 2016). This raises a number of related questions that are worthy of further investigation. For example, are club directors supportive of the increased professionalisation of the role of the football manager? If so, does this professionalisation have any influence on job tenure? Questions also arise for governing bodies at national and transnational level. For example, given the evidence on managerial job tenure and 
managerial longevity, to what extent does the Pro-Licence system inadvertently offer false hope to its successful candidates?

\section{References}

Blackett, A.D., Evans, A., \& Piggott, D. (2017). Why 'the best way of learning to coach the game is playing the game': conceptualising 'fast-tracked' high performance coaching pathway. Sport, Education and Society, 22, 744-758.

Bourdieu, P. (1977). Outline of a theory of practice. Cambridge: Cambridge University Press.

Bourdieu, P. (1978). Sport and social class. Social Science Information. 17, 819-840.

Bourdieu, P. (1984). Distinction: A social critique of the judgement of taste. Translated by Richard Nice. Cambridge, Massachusetts: Harvard University Press.

Bourdieu, P. (1990). The logic of practice. Cambridge: Polity Press.

Bourdieu, P. (1993). Concluding remarks: For a sociogenetic understanding of intellectual works. In C. Calhoun, E. Lipuma, \& M. Postone (Eds.), Bourdieu: Critical perspectives, (pp. 263-275). Cambridge: Polity Press.

Bourdieu, P. (2006). The forms of capital (1986). In I.Szeman, \& T.Kaposy (Eds.), Cultural theory: An anthology, (pp. 81-97). Chichester: Wiley Blackwell.

Bourdieu, P., \& Wacquant, L. (1992). Invitation to reflexive sociology. Cambridge: Polity Press.

Bridgewater, S. (2010). Football management. Palgrave: Basingstoke.

Bryman A., \& Bell, E. (2015). Business research methods. (4 ${ }^{\text {th }}$ edition). Oxford: Oxford University Press.

Carter, N. (2006). The football manager: a history. London: Routledge.

Collins, T. (2013). Sport in a capitalist society. London: Routledge.

Cooper C., \& Joyce, Y, (2013). Insolvency practice in the field of football. Accounting, Organizations \& Society, 38, 108-129. 
Cushion, C. J. (2011). Pierre Bourdieu: A theory of (coaching) practice. In R. L. Jones, P. Potrac, C. Cushion, \& L. T. Ronglan (Eds.), The sociology of sports coaching, (pp. 4053). London: Routledge.

Cushion, C.J., Armour, K.M., \& Jones, R.L. (2003). Coach education and continuing professional development: experience and learning to coach. Quest, 55, 215-230.

Cushion, C.J., \& Jones, R.L. (2006). Power, discourse and symbolic violence in professional youth soccer: The case of Albion Football Club. Sociology of Sport Journal, 23, 142161,

Cushion, C.J., \& Jones, R.L. (2014). A Bourdieusian analysis of cultural reproduction: socialisation and the 'hidden curriculum' in professional football. Sport, Education and Society, 19, 276-298.

DeLuca, J.R., \& Andrews, D.L. (2016). Exercising privilege: The cyclical reproduction of capital through swim club membership. Sociological Inquiry, 86, 301-323.

Deci E.L., \& Ryan, R.M. (1985). Intrinsic motivation and self-determination in human behaviour. New York: Plenum Press.

Dobson, S., \& Goddard, J. (2011). The economics of football. Cambridge: Cambridge University Press.

Emirbayer, M., \& Johnson, V. (2008). Bourdieu and organizational analysis. Theory \& Society, 37, 1-44.

Football Association (2016). The FA UEFA Pro-Licence. Retrieved from: http://www.thefa.com/st-georges-park/fa-learning/fa-national-courses/the-fa-uefa-prolicence accessed 25 January 2016.

Fry, J., Bloyce, D., \& Pritchard, I. (2015). Professional golf - A license to spend money? Issues of money in the lives of touring professional golfers. Journal of Sport and Social Issues, 39, 179-201. 
Gammelsæter, H. (2010). Institutional pluralism and governance in commercialized sport. European Sport Management Quarterly, 10, 569-594.

Gammelsæter, H. (2013). Leader succession and effectiveness in team sport. A critical review of the coach succession literature. Sport, Business and Management: An International Journal. 3, 285 - 296.

Gearing, B. (1999). Narratives of identity among former professional footballers in the United Kingdom. Journal of Aging Studies, 13, 43-58.

Grenfell, M. (2015). Pierre Bourdieu on sport. In R. Giulianotti (Ed.), Routledge handbook of the sociology of sport, (pp. 61-71). Abingdon: Routledge.

Hamil, S., \& Morrow, S. (2011). Corporate social responsibility in the Scottish Premier League: Context and motivation. European Sport Management Quarterly, 11, 143-170. Iellatchitch, A., Mayrhofer, W., \& Meyer, M. (2003). Career fields: a small step towards a grand career theory? International Journal of Human Resource Management, 14, 728750.

Jarvie, G., \& Maguire, J. (1994). Sport and Leisure in Social Thought. London: Routledge. Jenkins, R. (2002). Pierre Bourdieu. Revised edition. London: Routledge.

Jones, R.L., Armour, K.M., \& Potrac, P. (2003). Constructing expert knowledge: A case study of a top-level professional soccer coach. Sport, Education and Society, 8, 213 219.

Kelly, S. (2008). Understanding the role of the football manager in Britain and Ireland: A Weberian approach. European Sport Management Quarterly, 8, 399-419.

Kelly, S. (2017). The role of the professional football manager. London: Routledge.

Kitchin, P.J., \& Howe, P.D. (2013). How can the social theory of Pierre Bourdieu assist sport management research? Sport Management Review, 16, 123-134. 
LMA (2016). Mid-season manager statistics. Report by the League Managers’ Association. 1st June 2015 - 31st December 2015.

Lenoir, R. (2006). Scientific habitus: Pierre Bourdieu and the collective individual. Theory, Culture \& Society, 23(6), 25-43.

Liew, J. (2016, 7 December). Why appointment of Ian Cathro at Hearts has inadvertently condemned all humans to extinction. The Telegraph. Retrieved from: http://www.telegraph.co.uk/football/2016/12/07/appointment-ian-cathro-hearts-hasinadvertently-condemned-humans/ accessed 25 January 2017.

Light, R.L., \& Evans, J.E. (2013). Dispositions of elite-level rugby coaches towards games sense: Characteristics of their coaching habitus. Sport, Education and Society, 18, 407423.

McGillivray, D., Fearn, R., \& McIntosh, A. (2005). Caught up in and by the beautiful game: A case study of Scottish professional footballers. Journal of Sport and Social Issues, 29, 102-123.

McGillivray D., \& McIntosh, A. (2006). Football is my life: Theorizing social practice in the Scottish professional. Sport in Society, 9, 371-387.

McLean, K.N., Mallet, C.J., \& Newcombe, P. (2012). Assessing coach motivation: The development of the coach motivation questionnaire (CMQ). Journal of Sport \& Exercise Psychology. 34, 184-207.

Maton, K. (2012). Habitus. In M. Grenfell (Ed.), Pierre Bourdieu: Key concepts, (2 ${ }^{\text {nd }}$ ed.), (pp. 48-64). Abingdon: Routledge.

Moore, R. (2012). Capital. In M. Grenfell (Ed.), Pierre Bourdieu: Key concepts, (2 ${ }^{\text {nd }}$ ed.), (pp. 98-113). Abingdon: Routledge. 
Morrow, S. (2014). Football finances. In J. Goddard, \& P. Sloane (Eds.) Handbook on the economics of football, (pp. 80-99). Cheltenham: Edward Elgar.

Morrow, S., \& Howieson, B. (2014). The new business of football: A study of aspirant and current football club managers. The Journal of Sport Management, 28, 515-528.

Murray, E. (2016, December 6). Ian Cathro debate shows Scottish football is still in the dark age. The Guardian. Retrieved from:

https://www.theguardian.com/football/blog/2016/dec/06/scottish-football-hearts-iancathro-sfa-malky-mackay accessed 25 January 2017.

Potrac, P, Jones, R., \& Armour, K. (2002). It's all about getting respect: The coaching behaviours of an expert English soccer coach. Sports, Education and Society, 7, 183202.

Nissen, R. (2016). Hired to be fired in Danish professional football. International Journal of Sport Science and Coaching, 11, 137-148.

Ryan, R.M., \& Deci, E.L. (2000). Intrinsic and extrinsic motivations: Classic definitions and new directions. Contemporary Educational Psychology, 25, 54-67.

Schinkel, W. (2007). Sociological discourse of the relational: the cases of Bourdieu \& Latour, The Sociological Review, 55, 707-729.

Schubert, J.D. (2012). Suffering/symbolic violence. In M. Grenfell (Ed.), Pierre Bourdieu: Key concepts, (2 ${ }^{\text {nd }}$ ed.), (pp. 179-194). Abingdon: Routledge.

Scottish FA (2016). UEFA Pro-Licence. Retrieved from: http://www.scottishfa.co.uk/scottish_football.cfm?page=3565 accessed 25 January 2016.

Sparkes, A. C., \& Smith, B. (2014). Qualitative research methods in sport, exercise and health: From process to product. London: Routledge. 
Thomson, P. (2012). Field. In M. Grenfell (Ed.), Pierre Bourdieu: Key concepts $\left(2^{\text {nd }}\right.$ ed), (pp. 65-82). Abingdon: Routledge.

Tomlinson, A. (2004). Pierre Bourdieu and the sociological study of sport. In R. Giulianotti (Ed.), Sport and modern social theorists, (pp. 161-172). London: MacMillan.

Townsend, R., \& Cushion, C. (2017). Elite cricket coach education: a Bourdieusian analysis. Sport, Education and Society, 22, 528-546.

UEFA (2012). Financial fair play and club licensing regulations. Edition 2012. Nyon: UEFA.

Vamplew, W. (1988). Pay up and play the game: Professional sport in Britain, 1875-914. Cambridge: Cambridge University Press.

Vaughan, D. (2002). Signals and interpretive work: The role of culture in a theory of practical action. In K. A. Cerulo (Ed.), Culture in mind: Toward a sociology of culture and cognition (pp. 28-56). New York: Routledge.

Webb. J., Schirato, T., \& Danaher, G. (2002). Understanding Bourdieu. London: Sage.

Wilders, M.G. (1976). The football club manager - A precarious occupation? The Journal of Management Studies, 13, 152-163. 
Table 1

Pro-Licence candidate background

\begin{tabular}{|c|c|c|c|c|c|c|c|}
\hline \multirow[b]{3}{*}{ Interviewee } & \multicolumn{3}{|c|}{ Post-playing experience } & \multicolumn{3}{|c|}{ Professional playing experience } & \multirow{3}{*}{$\begin{array}{c}\text { Academic } \\
\text { qualifications }{ }^{1}\end{array}$} \\
\hline & \multicolumn{2}{|c|}{ At interview date } & \multirow{2}{*}{$\begin{array}{l}\text { Subsequent } \\
\text { role as Manager* }\end{array}$} & \multirow{2}{*}{$\begin{array}{c}\text { Elite } \\
\text { national }^{2}\end{array}$} & \multirow[t]{2}{*}{ Overseas } & \multirow{2}{*}{$\begin{array}{l}\text { National } \\
\text { caps }\end{array}$} & \\
\hline & Position held & Age & & & & & \\
\hline 1. & Player & 40 & Yes & Yes & No & Yes & No \\
\hline 2. & No paid football role & 40 & Yes & Yes & Yes & Yes & Highers/A-levels \\
\hline 3. & Assistant Manager & 40 & No & Yes & Yes & No & $\begin{array}{l}\text { University degree } \\
\text { post-playing }\end{array}$ \\
\hline 4. & First team coach & 41 & No & Yes & No & No & No \\
\hline 5. & $\begin{array}{l}\text { Head Coach, US } \\
\text { collegiate }\end{array}$ & 43 & No & No & No & No & University degree \\
\hline 6. & No paid football role & 43 & No & Yes & Yes & Yes & No \\
\hline 7. & Assistant manager & 38 & Yes & Yes $^{3}$ & No & Yes & No \\
\hline 8. & First team coach & 44 & Yes & Yes & No & No & No \\
\hline 9. & $\begin{array}{l}\text { Coach - National age } \\
\text { group }\end{array}$ & 42 & $\mathrm{Yes}^{4}$ & Yes & No & Yes & No \\
\hline 10. & Assistant Manager & 36 & Yes & Yes & No & No & No \\
\hline 11. & Head Coach, US college & 47 & No & No & No & No & University degree \\
\hline 12. & $\begin{array}{l}\text { National Association } \\
\text { employee }\end{array}$ & 41 & Yes & Yes & No & No & No \\
\hline 13. & Manager & 39 & Yes & Yes & No & No & No \\
\hline 14. & Manager & 47 & Yes & Yes & No & Yes & No \\
\hline 15. & No paid football role & 35 & No & Yes & No & No & Highers \\
\hline 16. & Reserve team manager & 40 & Yes & Yes & No & Yes & No \\
\hline 17. & No paid football role & 37 & Yes & Yes & No & No & No \\
\hline 18. & First team coach & 38 & No & Yes & No & Yes & No \\
\hline 19. & Player & 41 & Yes & EPL & No & Yes & University degree \\
\hline
\end{tabular}

* Professional club unless otherwise stated

\footnotetext{
${ }^{1}$ Defined as University-entry level qualifications or beyond (at date of interview).

${ }^{2}$ Defined as English Premier League, Scottish Premier League or female equivalent leagues.

${ }^{3}$ Football League.

${ }^{4}$ Semi-professional club.
} 